\title{
Mast cell-mediated neuroinflammation may have a role in attention deficit hyperactivity disorder (Review)
}

\author{
YUCHEN SONG* ${ }^{*}$ MANQI LU* ${ }^{*}$, HAIXIA YUAN, TIANYI CHEN and XINMIN HAN \\ Institute of Pediatrics of Traditional Chinese Medicine, First Clinical Medical College, \\ Nanjing University of Chinese Medicine, Nanjing, Jiangsu 210023, P.R. China
}

Received October 15, 2019; Accepted April 29, 2020

DOI: $10.3892 /$ etm.2020.8789

\begin{abstract}
Attention deficit hyperactivity disorder (ADHD) is a common neurodevelopmental and behavioral disorder with a serious negative impact on the quality of life from childhood until adulthood, which may cause academic failure, family disharmony and even social unrest. The pathogenesis of ADHD has remained to be fully elucidated, leading to difficulties in the treatment of this disease. Genetic and environmental factors contribute to the risk of ADHD development. Certain studies indicated that ADHD has high comorbidity with allergic and autoimmune diseases, with various patients with ADHD having a high inflammatory status. Increasing evidence indicated that mast cells (MCs) are involved in the pathogenesis of brain inflammation and neuropsychiatric disorders. MCs may cause or aggravate neuroinflammation via the selective release of inflammatory factors, interaction with glial cells and neurons, activation of the hypothalamic-pituitary adrenal axis or disruption of the blood-brain barrier integrity. In the present review, the notion that $\mathrm{MC}$ activation may be involved in the occurrence and development of ADHD through a number of ways is discussed based on previously published studies. The association between MCs and ADHD appears to lack sufficient evidence at present and this hypothesis is considered to be worthy of further study, providing a novel perspective for the treatment of ADHD.
\end{abstract}

Correspondence to: Professor Xinmin Han, Institute of Pediatrics of Traditional Chinese Medicine, First Clinical Medical College, Nanjing University of Chinese Medicine, 138 Xianlin Road, Qixia, Nanjing, Jiangsu 210023, P.R. China

E-mail: hxmtgzy@163.com

${ }^{*}$ Contributed equally

Key words: attention deficit hyperactivity disorder, mast cell, brain, neuroinflammation, microglia, blood-brain barrier, hypothalamic-pituitary adrenal axis

\section{Contents}

\section{Introduction}

2. Overview and activation of mast cells (MC)

3. MC-glia crosstalk

4. MC-neuron interactions

5. MCs and the hypothalamic-pituitary adrenal (HPA) axis

6. MCs and the blood-brain barrier (BBB)

7. Inflammation/MCs and attention deficit hyperactivity disorder (ADHD)

8. MCs in brain disorders

9. Possible association between ADHD and MCs

10. Conclusions

\section{Introduction}

ADHD is characterized by inattention, motor hyperactivity and impulsivity, affecting childhood and adolescence until adulthood. ADHD is a childhood-onset neurodevelopmental disorder with a worldwide prevalence of 1.4-3.0\% (1). ADHD is associated with substance misuse, oppositional defiant disorder, conduct disorder, depression, post-traumatic stress disorder (PTSD), school or occupational failure and criminality, and these comorbidities may even lead to increased mortality in adulthood $(2,3)$. Half of the patients with ADHD have impairing symptoms persisting into adolescence and $30-60 \%$ into adulthood (4). Therefore, the pathogenesis and causes of ADHD warrant more attention.

The etiology of ADHD is complex, and genetic and environmental factors have a role in it (1). ADHD is a familial disorder with high heritability that ranges between 60 and 90\% (5). Psychosocial risks, such as low income, family adversity and hostile parenting, are strongly related to ADHD and other psychiatric disorders (6). The relative risk of ADHD is 5-9 in first-degree relatives of probands with ADHD (5). Several different classes of genomic variants have been identified to be associated with ADHD (6). Candidate gene studies have revealed the effects of genes associated with monoamine neurotransmitter systems (1). The composite genetic risk scores and copy number variants exhibit a significant overlap between ADHD and schizophrenia and mood disorders (7). In addition, environmental factors are significant risk factors for ADHD. Several lines of clinical evidence suggest that 
prenatal and perinatal factors, environmental toxins, and dietary and psychosocial factors may be potential risk factors for ADHD (8). In-utero exposure to maternal stress, cigarettes, alcohol, prescribed drugs (e.g., paracetamol) and illegal drugs were reported to be associated with ADHD (9). Psychosocial risks, including low income, family adversity and harsh or hostile parenting, have also been demonstrated to be associated with ADHD and several other psychiatric disorders, such as autism spectrum disorder (ASD) and obsessive-compulsive disorder (10-12). The occurrence of ADHD is based on the combined effects of genetic and environmental factors.

Although ADHD is a heterogeneous disorder and the pathogenesis has not been fully elucidated, studies in animal models have suggested the involvement of dopaminergic, noradrenergic and serotoninergic neurotransmission $(11,13)$. Structural and functional abnormalities in the cortical and subcortical regions of the brain are also considered to be characteristic of ADHD. For instance, a study including imaging data of $>3,000$ patients with ADHD suggested that the volume of the nucleus accumbens, amygdala, caudate nucleus, hippocampus and putamen was reduced (14). Methylphenidate (MPH), the first-line medical treatment for ADHD, may cause side effects, including depression, compulsion and loss of appetite (15). Furthermore, a certain proportion of patients taking MPH did not achieve the expected outcomes (16). To improve the treatment of ADHD, it may thus be worthwhile to gain novel insight into the pathological mechanisms.

Neuroinflammation acts as a double-edged sword, which is an epiphenomenon following neuronal cell damage and also an inherent host-defense mechanism to protect and restore the normal structure and function of the brain against infection and injury, contributing to the recovery of impaired neurons and to the occurrence and aggravation of neurodegeneration (17). Neuroinflammation, particularly when persistent, has an important role in central nervous system (CNS) disorders, including neuroimmune diseases, neurodegenerative diseases and other neuropsychiatric diseases, such as multiple sclerosis (MS) (18), Parkinson's disease (PD) (19), Alzheimer's disease (AD) (20), stroke (21), depression (22), autism (23), schizophrenia (24) and chronic pain (25). Neuroinflammation differs from inflammation at other sites with no dendritic cells involved. Microglia and mast cells (MCs), which are natural immune cells of the CNS, are mainly involved in the occurrence of neuroinflammation (26). Astrocytes are also involved in neuroinflammation (27).

Microglia are the most widely studied cell type involved in CNS inflammation (26). As the major immune effector cells of the brain, microglia continuously monitor the surrounding environment and provide an immunosurveillance function for brain damage (26). Microglia function in maintaining the neuronal synapses, identifying pathogens, removing cellular debris and providing nutritional support (28). In addition, CNS neuroinflammation also involves neurons, astrocytes, MCs, T cells and pericytes. Microglia and MCs, both derived from hematopoietic progenitor cells, are two tracks to the path of neuroinflammation (29). Previous studies on inflammation in the brain have mainly focused on microglia and astrocytes (30-33). Recently, MCs have emerged as important factors in brain inflammation and are considered as the 'first responders' to brain injury (34). Based on the above studies, a hypothesis that ADHD onset may be associated with inflammation caused by MC activation was proposed and studies supporting this notion were discussed in the present review.

\section{Overview and activation of MCs}

Although the role of MCs is overlooked compared with microglia, MCs remain an important factor in the immune signaling pathway (29). MCs, the effector cells of the innate immune system, are derived from hematopoietic stem cells and multifunctional antigen-presenting cells and have a pivotal role in immunoglobulin type $\mathrm{E}(\mathrm{IgE})$-associated allergic and inflammation-associated diseases (35). Despite their low numbers in most organs, MCs are present in both healthy and disease states. MCs are the first line of defense against invading pathogens and are distributed in almost all organs and vascularized tissues (36). Blood MCs express CD34 and contain cytoplasmic granules filled with heparin and histamine, the latter of which is released after binding to IgE. Unlike other myeloid-derived cells, tissue MCs have a hematopoietic developmental lineage $(37,38)$. During MC development, immature lineage progenitors enter the circulation and are recruited to peripheral tissues by endothelial cells, regulating the appearance of granules with proteases $(37,38)$. Human MCs may be classified into mucosal and connective tissue types according to the type of proteases present in their cytoplasmic granules; the mucosal type contains tryptase, whereas the connective tissue type contains both tryptase and chymase (39). MCs act as first responders and environmental 'sensors' to interact with other cellular elements involved in physiological and immune responses, promoting the neuroinflammation process (40). MCs are present in various areas of the brain and meninges. Although less distributed in the brain, they are generally found in the subthalamic nucleus, choroid plexus and the parenchyma of the hypothalamic region (41). The pathogenic roles of MCs were indicated to extend from allergic disease to autoimmune diseases and carcinogenesis (42-47).

The most common way through which MCs perform their function is degranulation. The activation of the inflammatory process results in a rapid release of $\mathrm{MC}$ granules into the interstitium. MC granules contain pre-formed and newly synthesized reactive chemicals known as MC mediators. These mediators include histamine, tryptase, chymase, interleukin families, tumor necrosis factor- $\alpha$ (TNF- $\alpha)$, serotonin, heparin, proteoglycans, vascular endothelial growth factor (VEGF), prostaglandins, leukotrienes, chemokines and growth factors, several of these are unique to MCs $(42,48)$. Studies have indicated that $\mathrm{MC}$ degranulation may cause cognitive dysfunction (49). Large-scale MC degranulation may cause fatal anaphylaxis; however, most physiological functions of MCs, including regulation of inflammatory processes, occur without complete degranulation (50). MCs are phenotypically and functionally heterogeneous. The pathways and results of MC activation are multifaceted. In addition to IgE, MCs may also be activated through a number of other stimuli, including trauma, other immunoglobulins, complements, toll-like receptors (TLRs), neuropeptides, cytokines, chemokines and other inflammatory products, causing mast cell activation and leading to the selective release of mediators and/or stimulating T-cell proliferation, differentiation and migration $(51,52)$. A 
characteristic of MC physiology that has been overlooked is that MCs are able to secrete mediators via differential or selective release without significant degranulation. This process may be regulated by the action of distinct protein kinases on a unique phosphoprotein (53). MCs undergo changes in the core of the electron-dense granules but without overt degranulation, a process that has been termed as activation, intragranular activation or piecemeal degranulation (54). MCs are essential for the pathogenesis of numerous inflammatory diseases, but this effect may only be achieved if MCs release selective mediators without degranulation, which may otherwise cause allergic reactions (52). Under normal circumstances, the brain does not express IgE receptor (FceRI), since the brain does not display any allergic reactions and $\operatorname{IgE}$ does not cross the blood-brain barrier (BBB) under normal conditions (55).

The ways in which the mediators are secreted depend on the given stimuli and microenvironmental conditions. For instance, serotonin may be selectively released without histamine or arachidonic acid metabolites (56). The combination of TLR4 and mast cells does not cause degranulation but results in the secretion of inflammation-associated mediators. TLR4 binds to the co-receptors CD14 and MD-2 expressed by MCs. Subsequently, activation by myeloid differentiation primary response protein MyD88 innate immune signal transduction adaptor results in activation of interleukin (IL) receptor-associated kinase family members and pyruvate dehydrogenase kinase isoform 1 , mitogen-activated protein kinases (MAPKs) p38 and JNK and to phospholipase A2 (57). TLR4 also binds to lipopolysaccharides (LPS) and induces TNF- $\alpha$ release without degranulation (58). LPS induces secretion of IL-5, IL-10 and IL-13 but not granulocyte-macrophage colony-stimulating factor, IL-1 or leukotriene $\mathrm{C}_{4}\left(\mathrm{LTC}_{4}\right)$ (58). The selective release of IL-6 occurs in the MC response to LPS, provided the presence of the PI3K inhibitor wortmannin or stem cell factors (59). Corticotropin-releasing hormone (CRH) was demonstrated to stimulate the selective release of VEGF without degranulation and histamine or tryptase release from the human leukemic mast cell line HMC-1 and human umbilical cord blood-derived mast cells (60). Neurotensin (NT) induces expression of CRH receptor (CRHR)-1 on MCs and NT and CRH are released under stress via NT-CRH crosstalk (61). IL-1 stimulates human MCs to selectively release IL- 6 without degranulation, via a unique process utilizing $40-80 \mathrm{~nm}$ vesicles unrelated to the length of secretory granules $(800-1,000 \mathrm{~nm})(62)$. IL-33 may serve as a potent activator of MCs and was reported to promote MC survival, maturation, migration and adhesion, and to selectively produce a variety of pro-inflammatory cytokines, including IL-4, IL-5, IL-6, IL-8 and IL-13 and chemokines including macrophage inflammatory protein-1 $\alpha$ and monocyte chemoattractant protein 1 (MCP-1) $(63,64)$. IL-33 enhances the role of the pro-inflammatory peptide substance $\mathrm{P}$ in stimulating human MCs to secrete high levels of VEGF and TNF via the interaction of neurokinin 1 and ST2 receptors without concomitant secretion of tryptase (65). In the presence of stem cell factor, IL-33 may also induce TNF production in MCs via a MAPK-activated protein kinases 2 and 3, ERK1/2- and PI3K-dependent pathways (66). Understanding the selective release of mediators may explain how MCs participate in numerous biological processes and how they are capable of exerting both immunostimulatory and immunosuppressive effects.

\section{MC-glia crosstalk}

Microglia and MCs are the two most important cell types mediating and regulating neuroinflammation in the brain. There is a close association between MCs and glial cells. MCs are generally clustered near the glia in neuroinflammatory conditions to recruit and activate other inflammatory cells, where neuroinflammation already occurs in the brain. The contribution of MCs and glia to neuroinflammation is strongly influenced by the likelihood of their crosstalk and pathological exacerbation (29). MCs may interact with microglia and astrocytes via the complement system, proteases, TLRs and chemokines. MCs may participate in the migration and activation of glia, thereby affecting the release of inflammatory mediators. The expression of ligand-receptor pairings may be upregulated under inflammatory conditions, facilitating chemotactic actions through contact between MC and glia (27). For instance, C5a, the chemoattractant anaphylatoxin peptide and its receptor CD88 are upregulated in the glia of inflammatory CNS tissues (67-69). Complementary expression of the C5a receptor on activated MCs produces an intense chemoattractant signal to the C5a peptide and intense crosstalk between C5a and TLR4, which also has a role in neuroinflammation (67-69). TLRs are a major class of pattern recognition receptors involved in innate immunity. TLRs are associated with groups of pathogens recognized by innate immune system cells, including microglia and MCs, and act as a bridge between non-specific and specific immunity (70). Upregulation of C-C motif chemokine 5 (CCL5; also known as RANTES) by MC activation leads to a pro-inflammatory response in microglia, releasing IL- 6 and CCL5, which in turn promotes chemokine expression in MC (71). IL-33 is an activator of MCs and IL-33 release from astrocytes may activate brain MCs and microglia (72). The binding of IL-33 to MC receptors leads to the secretion of IL-6, IL-13 and MCP-1 to regulate microglia activity. Furthermore, IL-33 may be stimulated from microglia pre-activated with pathogen-associated molecular patterns via TLRs $(73,74)$. Together, MC protease and matrix metalloproteinase (MMP) activate $\mathrm{p} 38$, ERK1/2, MAPKs and transcription factors including NF- $\mathrm{KB}$ in astrocytes, microglia and MCs (75). IL- 6 and TNF- $\alpha$ released from microglia upregulate protease-activated receptor 2 (PAR2) expression in MCs, causing MC activation and TNF- $\alpha$ release (76). MC tryptase may induce the release of pro-inflammatory mediators such as TNF- $\alpha$, IL- 6 and reactive oxygen species (ROS) via the PAR2/MAPK/NF- $\kappa \mathrm{B}$ signaling pathway and activation of PAR2 receptors on MCs, which then contributes to the development of microglia-mediated inflammation in the brain (77). IL-6 induces IL-13 release from MCs, affecting the expression of TLR2/TLR4. Furthermore, TNF- $\alpha$ upregulates PAR2 expression in MCs and enhances PAR2-mediated MC activation and degranulation (78-80). C-X-C chemokine receptor type 4 (CXCR4; also known as stromal cell-derived factor 1) is an MC chemotaxin and studies have indicated that 
CXCR4 is upregulated in hypoxia and ischemia, promoting the migration and activation of microglia (81). In addition to microglia, astrocytes sharing a perivascular localization with MCs maintain the viability of MCs. Astrocytes express histamine receptors and release cytokines/chemokines through Rho-family GTPases/ $\mathrm{Ca}^{2+}$-dependent protein kinase $\mathrm{C}$ isoforms, MAPK, NF- $\kappa \mathrm{B}$ and signal transducer and activator of transcription 1 (82-84). These trigger MC degranulation and enhance CD40L and CD40 surface expression, leading to further inflammation (82-84). Both microglia and astrocytes express histamine receptor $\mathrm{H}_{1}$ $\left(\mathrm{HRH}_{1}\right), \mathrm{HRH}_{2}$ and $\mathrm{HRH}_{3}$ and MCs may affect the activity of microglia and astrocytes through these receptors $(85,86)$. An in vitro study has indicated that MC proteases may induce demyelination and apoptosis of oligodendrocytes, while myelin promotes MC degranulation (87). Several experiments have confirmed the relationship between MCs and glia. Co-culture of microglia and HMC-1 cells revealed that activated HMC-1 cells stimulate the activation of microglia and subsequent production of pro-inflammatory factors TNF- $\alpha$ and IL-6 (88). MC degranulator compound $48 / 80$ induces microglia activation and inflammatory cytokine production, triggering an acute brain inflammatory response. However, the MC stabilizer cromolyn inhibits this effect, reduces inflammatory cytokines and inhibits the MAPK, AKT and NF- $\kappa$ B signaling pathways. Furthermore, cromolyn inhibits $\mathrm{HRH}_{1}, \mathrm{HRH}_{4}$, protease activity, PAR2 and TLR4 in microglia $(49,89)$. Incubation of astrocytes and neurons with 1-methyl-4-phenylpyridinium, glia maturation factor (GMF), mouse MC protease-6 (MMCP-6) and MMCP-7 increased PAR-2 expression, suggesting contact between MCs and astrocytes (90).

\section{MC-neuron interactions}

The connection between MCs and neurons mainly occurs through peripheral interactions. A number of studies have revealed the association between MCs and neurons in CNS neuroinflammation. In the brain, the co-localization of MCs and neurons provides a basis for neuroimmunological interactions. Cell adhesion molecule-1 (CADM1), expressed by mature hippocampal neurons, may have an important role in the development of MC neuron interactions (91). In the CNS, MC-derived products may enter adjacent neurons to insert their granular contents, a process known as granulation. In this way, MCs change the internal environment of neurons, presenting a novel form of neuroimmunological interaction (92). In addition, MCs express a series of neurotransmitter receptors, which may be directly activated, enhanced [neurokinin 1 receptor (NK1R), NK2R, NK3R and VIP receptor type 2] or inhibited (acetylcholine receptor) $(93,94)$. Furthermore, it was reported that activated MCs enhanced excitotoxic damage to $60 \%$ when co-cultured with hippocampal neurons. In $\mathrm{N}$-methyl-D-aspartate receptor-mediated synaptic neurotransmission, MC-derived histamine directly increases the death of hippocampal neurons (95). Tryptase released by MCs may directly activate proteinase-activated receptors on neurons and MC-derived TNF- $\alpha$ has a vital role in neuronal development, cell survival, synaptic plasticity and ionic homeostasis in the CNS (96). These MC-neuron interactions are thought to be involved in the pathogenesis of numerous neuroinflammatory diseases.

\section{MCs and the HPA axis}

The association between chronic stress and neuroinflammation has been confirmed by numerous studies. MCs have a vital role in the mechanism of brain damage caused by chronic stress on the brain. A variety of psychological and physiological stresses may lead to changes in the expression, distribution and activity of MCs in the CNS. Stress and pro-inflammatory cytokines activate the HPA axis, thus leading to an increase in $\mathrm{CRH}$ and arginine vasopressin release from the paraventricular nucleus of the hypothalamus. HPA axis activation also enhances the expression of $\mathrm{CRH}$ receptors, vascular permeability and $\mathrm{MC}$ activation (97). CRH released from MCs activates MCs and glia in the CNS in an autocrine and paracrine manner in the context of stress and neuroinflammation (98). In turn, activation of CNS MCs activates the HPA axis. MCs are located near $\mathrm{CRH}$-positive neurons in the median eminence and are closely linked to corticotropin-releasing factor receptors, which may be activated by CRH (99). This may be closely associated with the meningeal vasodilation and increased secretion of cytokines during meningeal inflammation in migraines (46). Cao et al (100) indicated that intravesical stress, CRH, MC activation and VEGFs have a crucial role in the stress-induced deterioration of inflammation, which may provide insight into the mechanism of brain stress. MC activation and $\mathrm{CRH}$ release increase BBB permeability, leading to further brain damage and contributing to chronic neuroinflammation in the brain $(60,101)$. Microglia express CRH receptors and activation of microglia by $\mathrm{CRH}$ leads to the release of harmful inflammatory mediators in psychiatric diseases, such as AD and pain $(102,103)$. Human MCs synthesize and secrete $\mathrm{CRH}$ and express functional CRH receptors (CRHR1 and CRHR2) (104). CRHR1-mediated activation of microglia induces microglia proliferation, TNF- $\alpha$ release and activation of MAPK. CRHR1 also mediates stress-induced MC degranulation (105). CRH release from activated MCs may also activate glial cells in neurodegenerative diseases such as AD $(103,106)$. Stressful conditions, including trauma or hypoxia, also activate peripheral MCs, which in turn activate $\mathrm{CRH}$ and substance $\mathrm{P}$ pathways, leading to BBB leakage and glial activation, causing further neuroinflammation and neurodegeneration (107). $\mathrm{CRH}$ concentrations are higher in brain regions prone to developing a pathology of AD (108). Elevated cortisol levels and HPA axis dysfunction are implicated in chronic stress, which releases amyloid beta $(\mathrm{A} \beta)$ that causes and/or worsens AD (109). CRHR1 antagonists have been indicated to decrease stress-mediated oxidative damage, prevent cognitive damage and loss of dendritic cells and reduce $A \beta$ deposition in the brain (110). These results confirm the correlation between $\mathrm{CRH}$ and AD. Other neuropeptides, including NT, may work with $\mathrm{CRH}$ to enhance MC activation and release of excessive inflammatory mediators under stress (61). CRH may enhance VEGF release from human MCs and induce FceRI expression in MCs, and this effect may be blocked by the natural flavone luteolin (111). CRH is also implicated in the pathogenesis of PD. Emotional chronic stress, which is closely associated with $\mathrm{CRH}$, enhances glial activation and aggravates neuronal death 
through inflammation in the substantia nigra of the brain of patients with PD (107). Furthermore, observations in animal models of PD indicate that stress-induced striatal damage may subsequently worsen motor symptoms (112).

\section{MCs and the BBB}

The BBB is composed of functional cerebral blood vessels, which create a stable CNS environment and protect brain parenchymal cells from harmful substances in the immune cells and blood. The BBB consists of tightly connected endothelial junctions and several intact transmembrane proteins, including claudin and occludin, that ensure its integrity. The basal lamina, which is part of the extracellular matrix, connects the endothelial cells of the BBB to adjacent cell layers (113). BBB destruction involves the accumulation of multiple vascular and neurotoxic molecules within the brain parenchyma, decreased cerebral blood flow and hypoxia (114). MCs are present in the dura mater and meninges, as well as on the cerebral side of the $\mathrm{BBB}$, and MCs are in contact with the distal ends of the astrocytes (115). MCs may cross the BBB and blood-spinal cord barrier when the barrier is damaged by CNS pathologies. Inflammatory factors released by MC activation, including histamine, tryptase, chymotrypsin and TNF- $\alpha$, may regulate BBB permeability (116). Furthermore, TNF- $\alpha$ induces the expression of intercellular adhesion molecule 1 (ICAM-1) and allows leukocytes to enter the affected tissues in the brain (117). The me chanism by which MCs destroy the BBB and promote basal layer degradation may involve vascular activity and matrix degradation components of MCs. MCs affect the integrity of the BBB through MMPs, whose enzymatic activity may be regulated by tissue MMP inhibitors. These include histamine and protease chymase, trypsin and cathepsin G (118). Cathepsin G activates MMPs, which degrade most of the protein components of the neurovascular matrix (118). In cerebral ischemic disease, MC degranulation increases, and brain MCs affect the activation of acute microvascular gelatinases (MMP-2 and -9) by releasing proteases to affect $\mathrm{BBB}$ destruction. In addition, elevated levels of VEGF may cause BBB rupture, vascular leakage and edema, which in turn causes stroke $(119,120)$. This process extravasates glutamate and albumin, activates astrocytes, alters $\mathrm{K}^{+}$ homeostasis in the brain parenchyma and leads to excessive neuronal excitation and inflammatory cell entry $(119,120)$. In experimental autoimmune encephalomyelitis (EAE), activation of meningeal MCs leads to TNF- $\alpha$ production and early neutrophil recruitment (121). This promotes local BBB destruction, allowing initial immune cells to enter the CNS and aggravate neuroinflammation (121). An in vitro study revealed that TNF- $\alpha$ induces downregulation of tight junction proteins occludin, claudin-5 and vascular endothelial-cadherin via an increase in ROS, which leads to increased paracellular permeability (122). IL-6 participates in the effect of TNF- $\alpha$ on endothelial monolayers. TNF- $\alpha$ upregulates the expression of ICAM-1 and vascular cell adhesion molecule-1 on brain microvascular endothelial cells (123). ICAM-1 is involved in leukocyte adhesion to the endothelium and its upregulation and leukocyte-mediated BBB breakdown are one of the pathological mechanisms and characteristics of various brain inflammatory diseases, including MS (123). Brain MCs may induce post-operative cognitive dysfunction by destabilizing the BBB and acute stress may cause BBB breakdown by activating MCs $(88,124)$. In addition to cerebral ischemia, BBB destruction has also been detected in dementia, motor neuron disease, MS, AD and other neuropsychiatric disorders (125-128). Substance P, which is released following traumatic brain injury or under stress, activates MCs and glia, releasing neuroinflammatory mediators and increasing BBB permeability (129). The release of $\mathrm{CRH}$ from MCs contributes to the subsequent release of various neuroinflammatory and neurotoxic mediators, leading to BBB rupture and glial cell activation, chronic neuroinflammation in the brain and causing autism (130). Cromoglycate, a MC-stabilizing agent, reversed $\mathrm{BBB}$ destruction, brain edema and neutrophil recruitment post-ischemia by inhibiting MC activation in a stroke model (131).

\section{Inflammation/MCs and ADHD}

There appears to be a high comorbidity between ADHD and allergic, inflammatory and autoimmune diseases. Epidemiological studies revealed that allergic diseases or conditions are closely associated with psychological and behavioral problems in pre-school children (132). A prospective birth cohort study examining the association between atopic eczema (AE) and ADHD was conducted. The results of the study indicated that children with AE were susceptible to ADHD, which was more obvious when they were at a younger age (133). Among early preterm-born children, systemic inflammation during the first post-natal month appears to increase the risk of teacher-identified ADHD characteristics (134). A prospective cohort study of 23,645 patients in Denmark suggested that a personal or maternal history of autoimmune disease was linked to a high risk of ADHD (135). A cross-sectional study involving 2,500,118 individuals in Norway indicated that ADHD was associated with psoriasis and Crohn's disease among females (136).

Several clinical studies have reported elevated levels of pro-inflammatory factors in the blood of children with ADHD. A clinical trial in Taiwan involving 216 children with ADHD and 216 non-ADHD controls indicated that the levels of hemoglobin and 5-hydroxytryptamine receptor 3A (5-HT) in fasting venous blood were significantly lower in children with ADHD compared with controls, whereas IgE and eosinophil counts were elevated compared with controls (137). A genome-wide association analysis identified a link between ADHD and the gene encoding IL-1 receptor antagonist (138). An association study of 546 patients with ADHD and 546 controls demonstrated an association between cytokine family ciliary neurotrophic factor receptor and both adult and childhood ADHD (139). Inflammatory processes may also increase the risk of ADHD in obese individuals and peripheral inflammatory factor levels may aggravate the severity of ADHD core symptoms $(140,141)$. The incidence of obesity and neuropsychiatric diseases has risen rapidly over the past three decades in the US $(142,143)$. Epidemiological studies indicated that maternal obesity and metabolic dysfunction increase the risk of ADHD, ASD, anxiety, depression, schizophrenia and food addiction via the neuroinflammatory pathway $(144,145)$. A review revealed that microbiota-gut-brain axis interactions 
affect the pathogenesis of a variety of inflammation-associated disorders, including mood disorders, ASD, ADHD, MS and obesity (146). Evidence suggested that patients displaying symptoms of ADHD have higher serum cytokine levels compared with normal controls, including IL-1 $\beta$, IL-2, IL-6, IL-10, IL-13, IL-16, interferon (IFN)- $\gamma$ and TNF- $\alpha$ (147-150). An investigation on serum cytokine levels in children with ADHD indicated that Purkinje cell antibodies were associated with the ADHD group, suggesting that neuro-antibodies and cytokines may contribute to ADHD (151). Patients with ADHD administered MPH had lower cytokine levels compared with those of unmedicated patients with ADHD (152). These data suggested that patients with ADHD may be in a high inflammatory state and ADHD treatment reduces cytokine levels. However, most studies involving a number of cases only identified a slight association between ADHD and peripheral inflammation but did not further explore the underlying mechanisms. Several retrospective studies have indicated that perinatal infection, preterm birth and low birth weight are closely associated with the risk of ADHD-like symptoms $(150,153)$. White matter injury caused by preterm birth is associated with maternal inflammation, perinatal infections and oxygen supply interruption, and occurs through the activation of glia, excitotoxicity and oxidative stress. Inflammation and hypoxia in this process are risk factors for ASD, ADHD and other psychological disorders (154). However, several studies found no evidence supporting a link between ADHD and inflammation in the brain. In a study on depression and anxiety in from the Netherlands including 2,307 subjects indicated that there was no evidence that ADHD development was associated with dysregulation of inflammatory markers, and there was no interaction between ADHD symptoms and stress-associated affective disorders (155). Examination of the early gestational maternal C-reactive protein in maternal serum and the risk of ADHD in offspring suggests a lack of correlation (156). In addition to clinical studies, several animal studies have identified or confirmed the association between ADHD and inflammation. Kozlowska et al (157) concluded that there is an interaction between neurological and immune systems in ADHD pathogenesis. This conclusion was reached by examining the concentration of cytokines, chemokines, oxidative stress markers, metabolic parameters, steroid hormones and steroidogenic enzymes in the serum and/or tissues of spontaneously hypertensive rats (ADHD model) and Wistar Kyoto rats (control animals).

Several pieces of evidence indirectly revealed a possible association between ADHD and inflammation. For instance, vitamin $\mathrm{D}$ has a significant protective effect on inflammation, oxidative stress and certain neurotrophic factors. Neurotransmitter and vitamin D levels are lower in patients with ADHD compared with those in healthy children (158). Dietary antioxidant treatment may have a positive effect on nerve damage caused by inflammation, oxidative stress and immune dysfunction in ADHD (159). Iron deficiency is considered to be a possible physiological etiology in subsets of patients with ADHD and serum ferritin may be affected by a variety of conditions, including inflammatory status (160). A randomized double-blinded controlled trial revealed that children with ADHD have lower blood levels of long-chain polyunsaturated fatty acids (PUFAs) compared with children with no ADHD. Furthermore, following PUFA supplementation, children with ADHD exhibited improvements in ADHD-associated symptoms, thus supporting a link to pathways responsible for inflammation in the body (161).

The intestines have a profound effect on the entire body including the brain, and the role of gut-brain connections has gradually been discovered. Food allergy is a common condition in children and adolescents and is suggested to be one of the gastrointestinal tract triggers for numerous psychological and psychiatric conditions including depression, anxiety and ADHD $(162,163)$. A study indicated that the majority of food allergies/intolerances are mediated by $\mathrm{IgE}$. Following continuous food exposure, allergens may bind conjugated $\mathrm{IgE}$ to induce MC degranulation and the secretion of inflammatory mediators, including cytokines, histamines, leukotrienes and prostaglandin (164). IgE-mediated allergic reactions are referred to as immediate type hypersensitivities. In non-IgE-mediated reactions, the allergic response may be mediated by Ig-free light chains or other cells such as eosinophils, T cells and mast cells. Cell-mediated food allergy, which is classified as delayed-type hypersensitivity, does not involve Igs and symptom onset is observed from $1 \mathrm{~h}$ to days after ingestion of the food protein $(165,166)$. Food intake may affect the behavior of children with ADHD through a mechanism that involves a non-IgE-mediated, cell-mediated or non-allergic response (167). A cross-sectional study from China suggested that early food allergies in school-age children are associated with ADHD (168). Children with ADHD reacted severely to allergenic foods including cow's milk, wheat and eggs $(167,169)$. Studies have pointed out that for certain patients with ADHD, dietary restrictions may provide significant benefits (170). A case study reported on a 7-year-old boy with ADHD and severe IgG-mediated food allergy who presented reduced $\mathrm{IgG}$ antibody levels and improved behavior with dietary supplement intervention (171). However, several studies obtained negative results regarding the association between ADHD with food allergies (172). One potential reason for this may be the complexity of the IgE immune response to food allergens in the gastrointestinal tract falling between the tolerance and sensitization mechanisms (173). Based on conflicting results of research, it was hypothesized that ADHD is not caused by allergic reactions, but that ADHD itself is a (non-)allergic hypersensitivity disorder $(174,175)$. Food-derived allergens trigger a hypersensitivity reaction that causes ADHD-like symptoms, possibly via an IgE or non-IgE allergic response or a non-allergic mechanism (174). Food allergy is closely linked to MCs. MCs express various substances that may trigger enteric neurons, including tryptase, histamine, 5-HT, nerve growth factor and TNF- $\alpha$ (176). Allergic reactions in the intestines may affect behavior through intestinal mast cells, which may trigger intestinal neurons to transmit information to the CNS via afferent sensory pathways (177). Activated MCs increase IL-6 production through the mTOR pathway (178). IL-6 was indicated to induce behavioral defects and is enhanced in post-mortem brains of patients with ASD (179). In addition, gut microbes affect host social behavior through the alteration of brain neural circuits and food allergies may affect behaviors through gut bacteria. For instance, the bacteroidete/firmicute ratio was increased 


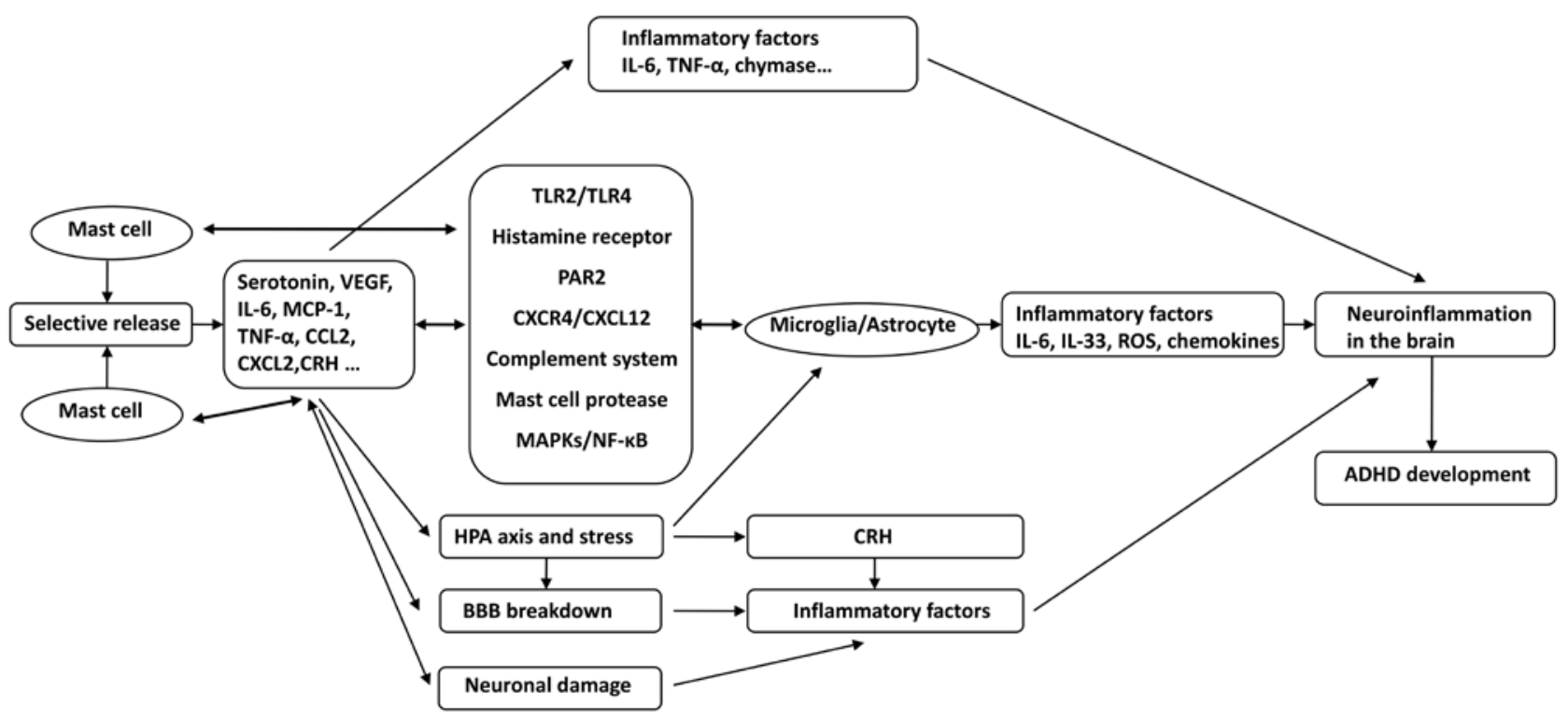

Figure 1. Possible association between ADHD and mast cells. Mast cells may cause ADHD via the following mechanisms: Selective release of inflammatory factors, interacting with glia via CD40L, TLR2/TLR4, histamine receptor, PAR2, CXCR4/CXCL12, complement system, mast cell protease, MAPKs and $\mathrm{NF}-\mathrm{\kappa B}$, causing neuronal damage, activating the HPA axis and resulting in BBB breakdown. These pathological processes trigger the neuroinflammation in the brain, resulting in the development and progression of ADHD. ADHD, attention deficit hyperactivity disorder; MAPK, mitogen-associated protein kinase; BBB, blood-brain barrier; CXCL/R, C-X-C motif chemokine ligand/receptor; CCL, C-C motif chemokine ligand; HPA, hypothalamic-pituitary adrenal; IL, interleukin; ROS, reactive oxygen species; VEGF, vascular endothelial growth factor; MCP, monocyte chemoattractant protein; TNF, tumor necrosis factor; TLR, Toll-like receptor; CRH, corticotropin-releasing hormone; PAR2, protease-activated receptor 2.

in children with ASD and propionic acid produced by gut bacteria may increase locomotor activities and stereotyped behavior $(180,181)$.

\section{MCs in brain disorders}

Although the possible association between MCs and ADHD has not been previously reported, the role of MCs in other brain disorders has been confirmed. For instance, studies have suggested that patients suffering from PTSD have immune disorders with an excessive inflammatory response. Patients with PTSD exhibit chronic stress responses along with low-grade inflammation in the body. Furthermore, MCs are also dysregulated in combat soldiers (182). The number of MCs in the skin, gastrointestinal tract and respiratory tract of patients with PTSD is higher compared with that in individuals without PTSD (183). In addition, patients with PTSD have high levels of $\mathrm{CRH}$ and inflammatory factors, including serum IL-6, IL-1 $\beta$, TNF- $\alpha$ and IFN- $\gamma$. Increased expression of these factors may be linked to MC activation (184). MC-derived substance $\mathrm{P}$ markedly contributes to pain in patients with PTSD (185). Furthermore, PTSD is an important risk factor for several autoimmune and MC-associated diseases, including MS, rheumatoid arthritis, thyroiditis, lupus erythematosus and IBD (186). Multiple lines of evidence suggested that MC activation accelerates the pathogenesis of $\mathrm{AD}$ in high-risk brain injury, trauma, stress and PTSD. MCs are one of the first type of brain cell involved in the pathogenesis of AD and respond early to $A \beta$ formation (187). GMF regulates neuroinflammation via the NACHT, LRR and PYD domains-containing protein 3 inflammasome in brains of patients with AD (188). Enhanced IL-33 and GMF expression was observed in the vicinity of amyloid plaques and neurofibrillary tangles in human AD brains (189). In AD, increased ROS activates MCs to release inflammatory mediators and several MC-derived inflammatory mediators were reported to be involved in the pathogenesis and severity of AD (190). Mitochondrial uncoupling proteins (UCPs) are implicated in neurodegenerative diseases and MCs express UCP2 and UCP4 (191). The concentration of $\mathrm{CRH}$ is higher in areas prone to $\mathrm{AD}$-associated pathological changes (108). In the brain of a rat model of AD, chymotrypsin-like proteases surrounded the meninges and $\mathrm{A} \beta$ highly accumulated in cortical blood vessels, and these proteases are thought to affect $A \beta$ accumulation (192). MS is a chronic inflammatory disease of the CNS, characterized by demyelination, immune cell infiltration and axonal damage. MCs are present in perivascular demyelinating lesions associated with immune cell infiltration and in the CNS parenchyma and leptomeninges of patients with MS (193). MCs may regulate the transport of inflammatory cells through the BBB, thereby exerting effects on MS and EAE $(107,121)$. Levels of histamine and tryptase are elevated in the cerebrospinal fluid of patients with MS (194). MCs may also be involved in the pathogenesis of ASD. Serum and brain NT levels as are elevated in patients with ASD, which may cause MC activation (195). TNF- $\alpha$, IL-6, MCP-1 and granulocyte macrophage colony-stimulating factor were significantly increased in the brain tissue of patients with ASD (179). Inflammation may induce depression through different pathways. Elevated kynurenine levels are associated with depression in humans. Kynurenine promotes IgE-mediated reactions of MCs, including degranulation, $\mathrm{LTC}_{4}$ release and IL-13 production through activation of phospholipase C- $\gamma 1$, Akt, MAPK p38 and intracellular calcium release in an aryl hydrocarbon receptor-dependent manner, possibly modulating $\mathrm{MC}$ responses (196). Mastocytosis is a rare disease characterized by the accumulation and activation of MCs, 
with a prevalence of depression ranging from 40-70\% (197). A study of 54 patients with mastocytosis identified the role of MCs in the tryptophan (TRP) catabolic pathway leading to depression. The levels of TRP and serotonin were significantly lower in patients with mastocytosis compared with healthy subjects, with higher indoleamine-2,3-dioxygenase activity and higher levels of kynurenic and quinolinic acids (198). This demonstrated a TRP metabolism disorder in mastocytosis, and its association with perceived stress and depression, thereby indicating a close association between MCs and the development of depression.

\section{Possible association between ADHD and MCs}

Various pieces of evidence suggested that ADHD may be a neuroinflammatory disease and is closely linked to the activation of MCs. The role of neuroinflammation and MCs in various neuropsychiatric diseases, including ASD, AD, PD and depression, has been elucidated. However, no studies have assessed the role of MCs in ADHD. In the present review, it was hypothesized that ADHD is a neuroinflammatory disease in which MCs have an important role. The association between other brain diseases and MCs and the inflammation-associated signal cascade induced by MC activation allow for the hypothesis that MCs may induce the development and progression of ADHD through the following mechanisms: i) MCs selectively release various neuroinflammatory mediators, including IL-6, TNF- $\alpha$, CRH and MCP-1. ii) Microglial and astrocyte activation by MCs via CD40L, TLR2/TLR4, HRH, PAR2, CXCR4/CXCL12, the complement system, MC protease, MAPKs and NF- $\kappa$ B, causes an increased release of IL-6, IL-33, TNF- $\alpha$, ROS and other inflammatory factors; in turn, glia affect the activation of MCs through the above-mentioned pathways. These pathological processes trigger and exacerbate the state of inflammation in the brain. iii) MCs mediate alterations of co-localized neurons through CADM1, enhancing neuroimmune responses through a process called transgranulation. Mediators released from MCs affect neurodevelopment in the CNS, cause neuronal damage and trigger neuroinflammation. iv) Chronic stress-mediated activation of the HPA axis, which enhances $\mathrm{CRH}$ receptor expression and CNS MC activation, leads to microglia activation, increased BBB permeability and release of inflammatory mediators. v) Inflammatory mediators released by MC activation, including histamine, tryptase, chymase and TNF- $\alpha$, result in increased expression of MMPs, VEGF, ICAM-1, as well as decreased expression of occludin and claudin-5 and destruction of BBB integrity. Inflammatory factors and inflammatory cells then enter the brain tissue, aggravating neuroinflammation in the brain and causing the occurrence and progression of ADHD (Fig. 1). Our group will endeavor to explore and validate these hypotheses using clinical and in vivo experiments.

\section{Conclusions}

With the enhanced requirement for life quality, behavioral disorders such as ADHD are gaining increased attention. However, at present, there is no consensus on the etiology, pathogenesis and effective treatment of ADHD. The association between ADHD and immunity or inflammation has recently been discovered, but the underlying mechanisms have remained to be elucidated. Previous studies $(34,41,49,199)$ have reported that $\mathrm{MC}$ activation is an important mechanism in the progression of neuroinflammatory diseases. MCs are of significance and easily overlooked in the immune system of the CNS. Based on the study of ADHD and inflammation, as well as the association between MCs and other neuropsychiatric diseases, it is reasonable to speculate that MC-meditated neuroinflammation has a vital role in ADHD. MC activation may lead to the selective release of inflammatory factors and also affect the function of glial cells via a number of ways, which in turn promotes the occurrence of CNS neuroinflammation. In addition, brain MCs interact with neurons, the $\mathrm{BBB}$ and the HPA axis, aggravating neuroinflammation and disrupting brain function. MCs may promote CNS inflammation through various pathways, further leading to the occurrence and exacerbation of ADHD. In the present review, this hypothesis was discussed based on previously published studies. To the best of our knowledge, the association between MCs and ADHD appears to lack sufficient evidence at present and this hypothesis is worthy of further investigation using clinical studies and well-designed experiments. The present study provided a perspective of inflammatory mechanisms being accountable for ADHD. This hypothesis may expand the current understanding of the onset of ADHD and provide a novel target for the treatment of the condition.

\section{Acknowledgements}

The authors thank Dr Rongyi Zhou (The First Affiliated Hospital of Henan University of Chinese Medicine, Zhengzhou, China) and Dr Jichao Sun (The First Affiliated Hospital of Guangxi University of Chinese Medicine, Nanning, China) for their helpful advice, supervision and early studies in the field of ADHD.

\section{Funding}

The present study was supported by the National Natural Science Foundation of China (grant no. 81674023 and 81873342).

\section{Availability of data and materials}

Not applicable.

\section{Authors' contributions}

XH conceived and designed the topic of the review. YS and ML performed the literature search and wrote the manuscript. HY and TC reviewed and edited the manuscript. All authors read and approved the final manuscript.

\section{Ethics approval and consent to participate}

Not applicable.

\section{Patient consent for publication}

Not applicable. 


\section{Competing interests}

The authors declare that they have no competing interests.

\section{References}

1. Thapar A and Cooper M: Attention deficit hyperactivity disorder. Lancet 387: 1240-1250, 2016.

2. Dalsgaard S, Ostergaard SD, Leckman JF, Mortensen PB and Pedersen MG: Mortality in children, adolescents, and adults with attention deficit hyperactivity disorder: A nationwide cohort study. Lancet 385: 2190-2196, 2015.

3. Howlett JR, Campbell-Sills L, Jain S, Heeringa SG, Nock MK, Sun X, Ursano RJ and Stein MB: Attention deficit hyperactivity disorder and risk of posttraumatic stress and related disorders: A prospective longitudinal evaluation in U.S. army soldiers. J Trauma Stress 31: 909-918, 2018.

4. Ahmed R, Borst JM, Yong CW and Aslani P: Do parents of children with attention-deficit/hyperactivity disorder (ADHD) receive adequate information about the disorder and its treatments? A qualitative investigation. Patient Prefer Adherence 8: 661-670, 2014

5. Hawi Z, Cummins TD, Tong J, Johnson B, Lau R, Samarrai W and Bellgrove MA: The molecular genetic architecture of attention deficit hyperactivity disorder. Mol Psychiatry 20: 289-297, 2015.

6. Posner J, Polanczyk GV and Sonuga-Barke E: Attention-deficit hyperactivity disorder. Lancet 395: 450-462, 2020.

7. Williams NM, Zaharieva I, Martin A, Langley K, Mantripragada K, Fossdal R, Stefansson H, Stefansson K, Magnusson P, Gudmundsson OO, et al: Rare chromosomal deletions and duplications in attention-deficit hyperactivity disorder: A genome-wide analysis. Lancet 376: 1401-1408, 2010.

8. Thapar A, Cooper M, Eyre O and Langley K: What have we learnt about the causes of ADHD? J Child Psychol Psychiatry 54: 3-16, 2013.

9. Thompson JM, Waldie KE, Wall CR, Murphy R and Mitchell EA; ABC study group: Associations between acetaminophen use during pregnancy and ADHD symptoms measured at ages 7 and 11 years. PLoS One 9: e108210, 2014

10. Harold GT, Leve LD, Barrett D, Elam K, Neiderhiser JM, Natsuaki MN, Shaw DS, Reiss D and Thapar A: Biological and rearing mother influences on child ADHD symptoms: Revisiting the developmental interface between nature and nurture. J Child Psychol Psychiatry 54: 1038-1046, 2013.

11. Waltes R, Freitag CM, Herlt T, Lempp T, Seitz C, Palmason H, Meyer J and Chiocchetti AG: Impact of autism-associated genetic variants in interaction with environmental factors on ADHD comorbidities: An exploratory pilot study. J Neural Transm (Vienna) 126: 1679-1693, 2019.

12. Grisham JR, Fullana MA, Mataix-Cols D, Moffitt TE, Caspi A and Poulton R: Risk factors prospectively associated with adult obsessive-compulsive symptom dimensions and obsessive-compulsive disorder. Psychol Med 41: 2495-2506, 2011.

13. Russell VA: Overview of animal models of attention deficit hyperactivity disorder (ADHD). Curr Protoc Neurosci 9: 9-35, 2011.

14. Hoogman M, Bralten J, Hibar DP, Mennes M, Zwiers MP, Schweren LSJ, van Hulzen KJE, Medland SE, Shumskaya E, Jahanshad N, et al: Subcortical brain volume differences in participants with attention deficit hyperactivity disorder in children and adults: A cross-sectional mega-analysis. Lancet Psychiatry 4: 310-319, 2017.

15. Gurkan K, Bilgic A, Turkoglu S, Kilic BG, Aysev A and Uslu R Depression, anxiety and obsessive-compulsive symptoms and quality of life in children with attention-deficit hyperactivity disorder (ADHD) during three-month methylphenidate treatment. J Psychopharmacol 24: 1810-1818, 2010.

16. Wilens TE: Effects of methylphenidate on the catecholaminergic system in attention-deficit/hyperactivity disorder. J Clin Psychopharmacol 28 (3 Suppl 2): S46-S53, 2008.

17. Lyman M, Lloyd DG, Ji X, Vizcaychipi MP and Ma D: Neuroinflammation: The role and consequences. Neurosci Res 79: 1-12, 2014

18. Milo R, Korczyn AD, Manouchehri N and Stüve O: The temporal and causal relationship between inflammation and neurodegeneration in multiple sclerosis. Mult Scler 4: 1352458519886943 , 2019.
19. Varley J, Brooks DJ and Edison P: Imaging neuroinflammation in Alzheimer's disease and other dementias: Recent advances and future directions. Alzheimers Dement 11: 1110-1120, 2015.

20. Bradburn S, Murgatroyd C and Ray N: Neuroinflammation in mild cognitive impairment and Alzheimer's disease: A meta-analysis. Ageing Res Rev 50: 1-8, 2019.

21. Jayaraj RL, Azimullah S, Beiram R, Jalal FY and Rosenberg GA: Neuroinflammation: Friend and foe for ischemic stroke. J Neuroinflammation 16: 142, 2019.

22. Woelfer M, Kasties V, Kahlfuss S and Walter M: The role of depressive subtypes within the neuroinflammation hypothesis of major depressive disorder. Neuroscience 403: 93-110, 2019.

23. Matta SM, Hill-Yardin EL and Crack PJ: The influence of neuroinflammation in autism spectrum disorder. Brain Behav Immun 79: 75-90, 2019.

24. Calabrese V, Giordano J, Crupi R, Di Paola R, Ruggieri M, Bianchini R, Ontario ML, Cuzzocrea S and Calabrese EJ: Hormesis, cellular stress response and neuroinflammation in schizophrenia: Early onset versus late onset state. J Neurosci Res 95: 1182-1193, 2017.

25. Huh Y, Ji RR and Chen G: Neuroinflammation, bone marrow stem cells, and chronic pain. Front Immunol 8: 1014, 2017.

26. Lucas SM, Rothwell NJ and Gibson RM: The role of inflammation in CNS injury and disease. Br J Pharmacol 147 (Suppl 1): S232-S240, 2006.

27. Skaper SD, Facci L, Zusso M and Giusti P: An inflammation-centric view of neurological disease: Beyond the neuron. Front Cell Neurosci 12: 72, 2018.

28. Colonna M and Butovsky O: Microglia function in the central nervous system during health and neurodegeneration. Annu Rev Immunol 35: 441-468, 2017.

29. Skaper SD, Giusti P and Facci L: Microglia and mast cells: Two tracks on the road to neuroinflammation. FASEB J 26: 3103-3117, 2012.

30. Zhang CJ, Jiang M, Zhou H, Liu W, Wang C, Kang Z, Han B, Zhang Q, Chen X, Xiao J, et al: TLR-stimulated IRAKM activates caspase-8 inflammasome in microglia and promotes neuroinflammation. J Clin Invest 128: 5399-5412, 2018.

31. Xiong XY, Liu L and Yang QW: Functions and mechanisms of microglia/macrophages in neuroinflammation and neurogenesis after stroke. Prog Neurobiol 142: 23-44, 2016.

32. Colombo E and Farina C: Astrocytes: Key regulators of neuroinflammation. Trends Immunol 37: 608-620, 2016

33. Montoya A, Elgueta D, Campos J, Chovar O, Falcón P, Matus S, Alfaro I, Bono MR and Pacheco R: Dopamine receptor D3 signalling in astrocytes promotes neuroinflammation. J Neuroinflammation 16: 258, 2019.

34. Kempuraj D, Selvakumar GP, Thangavel R, Ahmed ME,Zaheer S, Raikwar SP, Iyer SS, Bhagavan SM, Beladakere-Ramaswamy S and Zaheer A: Mast cell activation in brain injury, stress, and post-traumatic stress disorder and Alzheimer's disease pathogenesis. Front Neurosci 11: 703, 2017.

35. Krystel-Whittemore M, Dileepan KN and Wood JG: Mast cell: A multi-functional master cell. Front Immunol 6: 620, 2016.

36. Gilfillan AM, Austin SJ and Metcalfe DD: Mast cell biology: Introduction and overview. Adv Exp Med Biol 716: 2-12, 2011.

37. Prussin C and Metcalfe DD: 4. IgE, mast cells, basophils, and eosinophils. J Allergy Clin Immunol 111 (Suppl 2): S486-S494, 2003.

38. Vyas H and Krishnaswamy G: Paul Ehrlich's 'Mastzellen'-from aniline dyes to DNA chip arrays: A historical review of developments in mast cell research. Methods Mol Biol 315: 3-11, 2006.

39. Irani AM and Schwartz LB: Human mast cell heterogeneity. Allergy Proc 15: 303-308, 1994.

40. da Silva EZ, Jamur MC and Oliver C: Mast cell function: A new vision of an old cell. J Histochem Cytochem 62: 698-738, 2014.

41. Polyzoidis S, Koletsa T, Panagiotidou S, Ashkan K and Theoharides TC: Mast cells in meningiomas and brain inflammation. J Neuroinflammation 12: 170, 2015.

42. Galli SJ and Tsai M: IgE and mast cells in allergic disease. Nat Med 18: 693-704, 2012.

43. Kritikou E, Kuiper J, Kovanen PT and Bot I: The impact of mast cells on cardiovascular diseases. Eur J Pharmacol 778: 103-115, 2016.

44. Sant GR, Kempuraj D, Marchand JE and Theoharides TC: The mast cell in interstitial cystitis: Role in pathophysiology and pathogenesis. Urology 69 (Suppl 4): S34-S40, 2007.

45. Suurmond J, van der Velden D, Kuiper J, Bot I and Toes RE Mast cells in rheumatic disease. Eur J Pharmacol 778: 116-124, 2016. 
46. Theoharides TC, Donelan J, Kandere-Grzybowska K and Konstantinidou A: The role of mast cells in migraine pathophysiology. Brain Res Brain Res Rev 49: 65-76, 2005.

47. Theoharides TC, Angelidou A, Alysandratos KD, Zhang B, Asadi S, Francis K, Toniato E and Kalogeromitros D: Mast cel activation and autism. Biochim Biophys Acta 1822: 34-41, 2012.

48. Boyce JA: Mast cells and eicosanoid mediators: A system of reciprocal paracrine and autocrine regulation. Immunol Rev 217: 168-185, 2007.

49. Dong H, Wang Y, Zhang X, Zhang X, Qian Y, Ding H and Zhang S: Stabilization of brain mast cells alleviates LPS-induced neuroinflammation by inhibiting microglia activation. Front Cell Neurosci 13: 191, 2019.

50. Forsythe P: Mast cells in neuroimmune interactions. Trends Neurosci 42: 43-55, 2019.

51. Theoharides TC, Kempuraj D, Tagen M, Conti $\mathrm{P}$ and Kalogeromitros D: Differential release of mast cell mediators and the pathogenesis of inflammation. Immunol Rev 217: 65-78, 2007.

52. Theoharides TC and Cochrane DE: Critical role of mast cells in inflammatory diseases and the effect of acute stress. J Neuroimmunol 146: 1-12, 2004.

53. Theoharides TC, Sieghart W, Greengard P and Douglas WW: Antiallergic drug cromolyn may inhibit histamine secretion by regulating phosphorylation of a mast cell protein. Science 207 : $80-82,1980$

54. Dvorak AM: Basophils and mast cells: Piecemeal degranulation in situ and ex vivo: A possible mechanism for cytokine-induced function in disease. Immunol Ser 57: 169-271, 1992.

55. Pang X,Letourneau R, Rozniecki JJ, Wang L and Theoharides TC: Definitive characterization of rat hypothalamic mast cells. Neuroscience 73: 889-902, 1996.

56. van Haaster CM, Engels W, Lemmens PJ, Hornstra G, van der Vusse GJ and Heemskerk JW: Differential release of histamine and prostaglandin D2 in rat peritoneal mast cells: Roles of cytosolic calcium and protein tyrosine kinases. Biochim Biophys Acta 1265: 79-88, 1995.

57. Lee CC, Avalos AM and Ploegh HL: Accessory molecules for Toll-like receptors and their function. Nat Rev Immunol 12 : 168-179, 2012

58. McCurdy JD, Olynych TJ, Maher LH and Marshall JS: Cutting edge: Distinct Toll-like receptor 2 activators selectively induce different classes of mediator production from human mast cells. J Immunol 170: 1625-1629, 2003.

59. Sismanopoulos N, Delivanis DA, Alysandratos KD, Angelidou A Therianou A, Kalogeromitros D and Theoharides TC: Mast cells in allergic and inflammatory diseases. Curr Pharm Des 18 2261-2277, 2012

60. Cao J, Cetrulo CL and Theoharides TC: Corticotropin-releasing hormone induces vascular endothelial growth factor release from human mast cells via the cAMP/protein kinase A/p38 mitogen-activated protein kinase pathway. Mol Pharmacol 69: 998-1006, 2006.

61. Alysandratos KD, Asadi S, Angelidou A, Zhang B Sismanopoulos N, Yang H, Critchfield A and Theoharides TC: Neurotensin and $\mathrm{CRH}$ interactions augment human mast cell activation. PLoS One 7: e48934, 2012.

62. Kandere-Grzybowska K, Letourneau R, Kempuraj D, Donelan J, Poplawski S, Boucher W, Athanassiou A and Theoharides TC: IL-1 induces vesicular secretion of IL-6 without degranulation from human mast cells. J Immunol 171: 4830-4836, 2003.

63. Bawazeer MA and Theoharides TC: IL-33 stimulates human mast cell release of CCL5 and CCL2 via MAPK and NF-kB, inhibited by methoxyluteolin. Eur J Pharmacol 865: 172760, 2019.

64. Theoharides TC and Leeman SE: Effect of IL-33 on de novo synthesized mediators from human mast cells. J Allergy Clin Immunol 143: 451, 2019.

65. Taracanova A, Tsilioni I, Conti P, Norwitz ER, Leeman SE and Theoharides TC: Substance P and IL-33 administered together stimulate a marked secretion of IL-1 $\beta$ from human mast cells, inhibited by methoxyluteolin. Proc Natl Acad Sci USA 115: E9381-E9390, 2018

66. Drube S, Kraft F, Dudeck J, Muller AL, Weber F, Gopfert C, Meininger I, Beyer M, Irmler I, Hafner $\mathrm{N}$, et al: $\mathrm{MK} 2 / 3$ are pivotal for IL-33-induced and mast cell-dependent leukocyte recruitment and the resulting skin inflammation. J Immunol 197: 3662-3668, 2016

67. Gasque P, Singhrao SK, Neal JW, Gotze O and Morgan BP Expression of the receptor for complement C5a (CD88) is up-regulated on reactive astrocytes, microglia, and endothelia cells in the inflamed human central nervous system. Am J Pathol 150: 31-41, 1997.
68. Pundir P, MacDonald CA and Kulka M: The novel receptor $\mathrm{C} 5 \mathrm{aR} 2$ is required for C5a-mediated human mast cell adhesion, migration, and proinflammatory mediator production. J Immunol 195: 2774-2787, 2015.

69. Yuan B, Fu F, Huang S, Lin C, Yang G, Ma K, Shi H and Yang Z: C5a/C5aR pathway plays a vital role in brain inflammatory injury via initiating fgl-2 in intracerebral hemorrhage. Mol Neurobiol 54: 6187-6197, 2017.

70. Perkins DJ and Vogel SN: Inflammation: Species-specific TLR signalling-insight into human disease. Nat Rev Rheumatol 12: 198-200, 2016.

71. Skaper SD: Impact of Inflammation on the blood-neural barrier and blood-nerve interface: From review to therapeutic preview. Int Rev Neurobiol 137: 29-45, 2017.

72. Yasuoka S, Kawanokuchi J, Parajuli B, Jin S, Doi Y, Noda M, Sonobe Y, Takeuchi H, Mizuno T and Suzumura A: Production and functions of IL-33 in the central nervous system. Brain Res 1385: 8-17, 2011.

73. Burnstock G, Krugel U, Abbracchio MP and Illes P: Purinergic signalling: From normal behaviour to pathological brain function. Prog Neurobiol 95: 229-274, 2011.

74. Chakraborty S, Kaushik DK, Gupta $M$ and Basu A: Inflammasome signaling at the heart of central nervous system pathology. J Neurosci Res 88: 1615-1631, 2010.

75. Kempuraj D, Thangavel R, Selvakumar GP, Ahmed ME,Zaheer S, Raikwar SP, Zahoor H, Saeed D, Dubova I, Giler G, et al: Mast cell proteases activate astrocytes and glia-neurons and release interleukin-33 by activating p38 and ERK1/2 MAPKs and NF- $\kappa B$. Mol Neurobiol 56: 1681-1693, 2019.

76. Zhang S, Zeng X, Yang H, Hu G and He S: Mast cell tryptase induces microglia activation via protease-activated receptor 2 signaling. Cell Physiol Biochem 29: 931-940, 2012.

77. Pietrzak A, Wierzbicki M, Wiktorska $M$ and Brzezinska-Blaszczyk E: Surface TLR2 and TLR4 expression on mature rat mast cells can be affected by some bacterial components and proinflammatory cytokines. Mediators Inflamm 2011: 427473, 2011.

78. Zhang H, Lin L, Yang H, Zhang Z, Yang X, Zhang L and $\mathrm{He} S$ : Induction of IL-13 production and upregulation of gene expression of protease activated receptors in P815 cells by IL-6. Cytokine 50: 138-145, 2010.

79. Zhang H, Yang H and He S: TNF increases expression of IL-4 and PARs in mast cells. Cell Physiol Biochem 26: 327-336, 2010.

80. Wang X, Li C, Chen Y, Hao Y, Zhou W, Chen C and Yu Z: Hypoxia enhances CXCR4 expression favoring microglia migration via HIF-1alpha activation. Biochem Biophys Res Commun 371: 283-288, 2008.

81. Wang Y, Huang J, Li Y and Yang GY: Roles of chemokine CXCL12 and its receptors in ischemic stroke. Curr Drug Targets 13: 166-172, 2012.

82. Dong Y and Benveniste EN: Immune function of astrocytes. Glia 36: 180-190, 2001.

83. Kim DY, Hong GU and Ro JY: Signal pathways in astrocytes activated by cross-talk between of astrocytes and mast cells through CD40-CD40L. J Neuroinflammation 8: 25, 2011.

84. Seeldrayers PA, Levin LA and Johnson D: Astrocytes support mast cell viability in vitro. J Neuroimmunol 36: 239-243, 1992.

85. Dong H, Zhang W, Zeng X, Hu G, Zhang H, He S and Zhang S: Histamine induces upregulated expression of histamine receptors and increases release of inflammatory mediators from microglia. Mol Neurobiol 49: 1487-1500, 2014

86. Mele T and Juric DM: Identification and pharmacological characterization of the histamine $\mathrm{H} 3$ receptor in cultured rat astrocytes. Eur J Pharmacol 720: 198-204, 2013.

87. Medic N, Vita F, Abbate R, Soranzo MR, Pacor S, Fabbretti E, Borelli V and Zabucchi G: Mast cell activation by myelin through scavenger receptor. J Neuroimmunol 200: 27-40, 2008.

88. Zhang S, Dong H, Zhang X, Li N, Sun J and Qian Y: Cerebral mast cells contribute to postoperative cognitive dysfunction by promoting blood brain barrier disruption. Behav Brain Res 298 (Pt B)158-166, 2016

89. Dong H, Zhang X, Wang Y, Zhou X, Qian Y and Zhang S: Suppression of brain mast cells degranulation inhibits microglial activation and central nervous system inflammation. Mol Neurobiol 54: 997-1007, 2017

90. Kempuraj D, Selvakumar GP, Thangavel R, Ahmed ME,Zaheer S, Kumar KK, Yelam A, Kaur H, Dubova I, Raikwar SP, et al: Glia maturation factor and mast cell-dependent expression of inflammatory mediators and proteinase activated receptor- 2 in neuroinflammation. J Alzheimers Dis 66: 1117-1129, 2018. 
91. Hagiyama M, Furuno T, Hosokawa Y, Iino T, Ito T, Inoue T, Nakanishi M, Murakami Y and Ito A: Enhanced nerve-mast cell interaction by a neuronal short isoform of cell adhesion molecule-1. J Immunol 186: 5983-5992, 2011.

92. Wilhelm M, Silver R and Silverman AJ: Central nervous system neurons acquire mast cell products via transgranulation. Eur J Neurosci 22: 2238-2248, 2005.

93. Kulka M, Sheen CH, Tancowny BP, Grammer LC and Schleimer RP: Neuropeptides activate human mast cell degranulation and chemokine production. Immunology 123: 398-410, 2008.

94. Masini E, Fantozzi R, Conti A, Blandina P, Brunelleschi S and Mannaioni PF: Mast cell heterogeneity in response to cholinergic stimulation. Int Arch Allergy Appl Immunol 77: 184-185, 1985.

95. Skaper SD, Facci L, Kee WJ and Strijbos PJ: Potentiation by histamine of synaptically mediated excitotoxicity in cultured hippocampal neurones: A possible role for mast cells J Neurochem 76: 47-55, 2001.

96. Ossovskaya VS and Bunnett NW: Protease-activated receptors: Contribution to physiology and disease. Physiol Rev 84 579-621, 2004.

97. Claes SJ: Corticotropin-releasing hormone $(\mathrm{CRH})$ in psychiatry: From stress to psychopathology. Ann Med 36: 50-61, 2004.

98. Karagkouni A, Alevizos M and Theoharides TC: Effect of stress on brain inflammation and multiple sclerosis. Autoimmun Rev 12: 947-953, 2013.

99. Cao J, Papadopoulou N, Kempuraj D, Boucher WS, Sugimoto K, Cetrulo CL and Theoharides TC: Human mast cells express corticotropin-releasing hormone $(\mathrm{CRH})$ receptors and $\mathrm{CRH}$ leads to selective secretion of vascular endothelial growth factor. J Immunol 174: 7665-7675, 2005.

100. Cao J, BoucherW,KempurajD, Donelan JM and Theoharides TC: Acute stress and intravesical corticotropin-releasing hormone induces mast cell dependent vascular endothelial growth factor release from mouse bladder explants. J Urol 176: 1208-1213, 2006

101. Rozniecki JJ, Sahagian GG, Kempuraj D, Tao K, Jocobson S, Zhang B and Theoharides TC: Brain metastases of mouse mammary adenocarcinoma is increased by acute stress. Brain Res 1366: 204-210, 2010.

102. Kritas SK, Caraffa A, Antinolfi P, Saggini A, Pantalone A, Rosati M, Tei M, Speziali A, Saggini R, Pandolfi F, et al: Nerve growth factor interactions with mast cells. Int J Immunopathol Pharmacol 27: 15-19, 2014.

103. Kempuraj D, Mentor S, Thangavel R, Ahmed ME, Selvakumar GP, Raikwar SP, Dubova I, Zaheer S, Iyer SS and Zaheer A: Mast cells in stress, pain, blood-brain barrier, neuroinflammation and Alzheimer's disease. Front Cell Neurosci 13 $54,2019$.

104. Papadopoulou NG, Oleson L, Kempuraj D, Donelan J, Cetrulo CL and Theoharides TC: Regulation of corticotropin-releasing hormone receptor- 2 expression in human cord blood-derived cultured mast cells. J Mol Endocrinol 35: R1-R8, 2005

105. Ayyadurai S, Gibson AJ,D'Costa S, Overman EL, Sommerville LJ, Poopal AC, Mackey E, Li Y and Moeser AJ: Frontline science: Corticotropin-releasing factor receptor subtype 1 is a critical modulator of mast cell degranulation and stress-induced pathophysiology. J Leukoc Biol 102: 1299-1312, 2017.

106. Kempuraj D, Papadopoulou NG, Lytinas M, Huang M, Kandere-Grzybowska K, Madhappan B, Boucher W, Christodoulou S, Athanassiou A and Theoharides TC: Corticotropin-releasing hormone and its structurally related urocortin are synthesized and secreted by human mast cells Endocrinology 145: 43-48, 2004.

107. Kempuraj D, Thangavel R, Selvakumar GP, Zaheer S, Ahmed ME, Raikwar SP, Zahoor H, Saeed D, Natteru PA, Iyer S and Zaheer A: Brain and peripheral atypical inflammatory mediators potentiate neuroinflammation and neurodegeneration. Front Cell Neurosci 11: 216, 2017.

108. Pedersen WA, McCullers D, Culmsee C, Haughey NJ, Herman JP and Mattson MP: Corticotropin-releasing hormone protects neurons against insults relevant to the pathogenesis of Alzheimer's disease. Neurobiol Dis 8: 492-503, 2001.

109. Morgese MG, Schiavone S and Trabace L: Emerging role of amyloid beta in stress response: Implication for depression and diabetes. Eur J Pharmacol 817: 22-29, 2017.

110. Zhang C and Rissman RA: Corticotropin-releasing factor receptor-1 modulates biomarkers of DNA oxidation in Alzheimer's disease mice. PLoS One 12: e181367, 2017.
111. Asadi S and Theoharides TC: Corticotropin-releasing hormone and extracellular mitochondria augment IgE-stimulated human mast-cell vascular endothelial growth factor release, which is inhibited by luteolin. J Neuroinflammation 9: 85, 2012.

112. de Pablos RM, Herrera AJ, Espinosa-Oliva AM, Sarmiento M, Munoz MF, Machado A and Venero JL: Chronic stress enhances microglia activation and exacerbates death of nigral dopaminergic neurons under conditions of inflammation. J Neuroinflammation 11: 34, 2014

113. Strbian D, Kovanen PT, Karjalainen-Lindsberg ML, Tatlisumak T and Lindsberg PJ: An emerging role of mast cells in cerebral ischemia and hemorrhage. Ann Med 41: 438-450, 2009.

114. Profaci CP, Munji RN, Pulido RS and Daneman R: The blood-brain barrier in health and disease: Important unanswered questions. J Exp Med 217: e20190062, 2020.

115. Silver R and Curley JP: Mast cells on the mind: New insights and opportunities. Trends Neurosci 36: 513-521, 2013.

116. Skaper SD: Mast cell-glia dialogue in chronic pain and neuropathic pain: Blood-brain barrier implications. CNS Neurol Disord Drug Targets 15: 1072-1078, 2016.

117. Lindsberg PJ, Strbian D and Karjalainen-Lindsberg ML: Mast cells as early responders in the regulation of acute blood-brain barrier changes after cerebral ischemia and hemorrhage. J Cereb Blood Flow Metab 30: 689-702, 2010.

118. Tchougounova E, Lundequist A, Fajardo I, Winberg JO, Abrink M and Pejler G: A key role for mast cell chymase in the activation of pro-matrix metalloprotease- 9 and pro-matrix metalloprotease-2. J Biol Chem 280: 9291-9296, 2005.

119. Lapilover EG, Lippmann K, Salar S, Maslarova A, Dreier JP, Heinemann U and Friedman A: Peri-infarct blood-brain barrier dysfunction facilitates induction of spreading depolarization associated with epileptiform discharges. Neurobiol Dis 48: 495-506, 2012

120. Mattila OS, Strbian D, Saksi J, Pikkarainen TO, Rantanen V, Tatlisumak T and Lindsberg PJ: Cerebral mast cells mediate blood-brain barrier disruption in acute experimental ischemic stroke through perivascular gelatinase activation. Stroke 42 . 3600-3605, 2011.

121. Christy AL, Walker ME, Hessner MJ and Brown MA: Mast cell activation and neutrophil recruitment promotes early and robust inflammation in the meninges in EAE. J Autoimmun 42: 50-61, 2013.

122. Rochfort KD and Cummins PM: Cytokine-mediated dysregulation of zonula occludens-1 properties in human brain microvascular endothelium. Microvasc Res 100: 48-53, 2015.

123. Liu H, Luiten PG, Eisel UL, Dejongste MJ and Schoemaker RG: Depression after myocardial infarction: TNF- $\alpha$-induced alterations of the blood-brain barrier and its putative therapeutic implications. Neurosci Biobehav Rev 37: 561-572, 2013.

124. Esposito P, Gheorghe D, Kandere K, Pang X, Connolly R, Jacobson S and Theoharides TC: Acute stress increases permeability of the blood-brain-barrier through activation of brain mast cells. Brain Res 888: 117-127, 2001.

125. Alvarez JI, Cayrol R and Prat A: Disruption of central nervous system barriers in multiple sclerosis. Biochim Biophys Acta 1812: 252-264, 2011.

126. Bell RD, Winkler EA, Sagare AP, Singh I, LaRue B, Deane R and Zlokovic BV: Pericytes control key neurovascular functions and neuronal phenotype in the adult brain and during brain aging. Neuron 68: 409-427, 2010.

127. Henkel JS, Beers DR, Wen S, Bowser R and Appel SH: Decreased mRNA expression of tight junction proteins in lumbar spinal cords of patients with ALS. Neurology 72: 1614-1616, 2009.

128. Khalil MH, Silverman AJ and Silver R: Mast cells in the rat brain synthesize gonadotropin-releasing hormone. J Neurobiol 56: $113-124,2003$

129. Corrigan F, Mander KA, Leonard AV and Vink R: Neurogenic inflammation after traumatic brain injury and its potentiation of classical inflammation. J Neuroinflammation 13: 264, 2016

130. Theoharides TC, Asadi S and Patel AB: Focal brain inflammation and autism. J Neuroinflammation 10: 46, 2013

131. Strbian D, Karjalainen-Lindsberg ML, Tatlisumak $T$ and Lindsberg PJ: Cerebral mast cells regulate early ischemic brain swelling and neutrophil accumulation. J Cereb Blood Flow Metab 26: 605-612, 2006.

132. van der Schans J, Pleiter JC, de Vries TW, Schuiling-Veninga CC, Bos JH, Hoekstra PJ and Hak E: Association between medication prescription for atopic diseases and attention-deficit/hyperactivity disorder. Ann Allergy Asthma Immunol 117: 186-191, 2016. 
133. Genuneit J, Braig S, Brandt S, Wabitsch M, Florath I, Brenner H and Rothenbacher D: Infant atopic eczema and subsequent attention-deficit/hyperactivity disorder-a prospective birth cohort study. Pediatr Allergy Immunol 25: 51-56, 2014

134. Allred EN, Dammann O, Fichorova RN, Hooper SR, Hunter SJ Joseph RM, Kuban K, Leviton A, O'Shea TM and Scott MN ELGAN Study ADHD symptoms writing group for the ELGAN Study Investigators: Systemic inflammation during the first postnatal month and the risk of attention deficit hyperactivity disorder characteristics among 10 year-old children born extremely preterm. J Neuroimmune Pharmacol 12: 531-543, 2017.

135. Nielsen PR, Benros ME and Dalsgaard S: Associations between autoimmune diseases and attention-deficit/hyperactivity disorder: A nationwide study. J Am Acad Child Adolesc Psychiatry 56: 234-240, 2017.

136. Hegvik TA, Instanes JT, Haavik J, Klungsoyr K and Engeland A: Associations between attention-deficit/hyperactivity disorder and autoimmune diseases are modified by sex: A population-based cross-sectional study. Eur Child Adolesc Psychiatry 27: 663-675, 2018.

137. Wang LJ, Yu YH, Fu ML, Yeh WT, Hsu JL, Yang YH, Chen WJ, Chiang BL and Pan WH: Attention deficit-hyperactivity disorder is associated with allergic symptoms and low levels of hemoglobin and serotonin. Sci Rep 8: 10229, 2018.

138. Segman RH, Meltzer A, Gross-Tsur V, Kosov A, Frisch A, Inbar E, Darvasi A, Levy S, Goltser T, Weizman A and Galili-Weisstub E: Preferential transmission of interleukin-1 receptor antagonist alleles in attention deficit hyperactivity disorder. Mol Psychiatry 7: 72-74, 2002.

139. Ribases M, Hervas A, Ramos-Quiroga JA, Bosch R, Bielsa A, Gastaminza X, Fernandez-Anguiano M, Nogueira M, Gomez-Barros N, Valero S, et al: Association study of 10 genes encoding neurotrophic factors and their receptors in adult and child attention-deficit/hyperactivity disorder. Biol Psychiatry 63 : 935-945, 2008.

140. Cortese S and Vincenzi B: Obesity and ADHD: Clinical and neurobiological implications. Curr Top Behav Neurosci 9: 199-218, 2012

141. Cortese S, Angriman M, Comencini E, Vincenzi B and Maffeis C: Association between inflammatory cytokines and ADHD symptoms in children and adolescents with obesity: A pilot study. Psychiatry Res 278: 7-11, 2019.

142. Boyle CA, Boulet S, Schieve LA, Cohen RA, Blumberg SJ, Yeargin-Allsopp M, Visser S and Kogan MD: Trends in the prevalence of developmental disabilities in US children, 1997-2008. Pediatrics 127: 1034-1042, 2011.

143. Olfson M, Blanco C, Wang S, Laje G and Correll CU: National trends in the mental health care of children, adolescents, and adults by office-based physicians. JAMA Psychiatry 71: 81-90, 2014.

144. Rivera HM, Christiansen KJ and Sullivan EL: The role of maternal obesity in the risk of neuropsychiatric disorders. Front Neurosci 9: 194, 2015.

145. Sullivan EL, Riper KM, Lockard R and Valleau JC: Maternal high-fat diet programming of the neuroendocrine system and behavior. Horm Behav 76: 153-161, 2015.

146. Petra AI, Panagiotidou S, Hatziagelaki E, Stewart JM, Conti P and Theoharides TC: Gut-microbiota-brain axis and its effect on neuropsychiatric disorders with suspected immune dysregulation. Clin Ther 37: 984-995, 2015.

147. Anand D, Colpo GD, Zeni G, Zeni CP and Teixeira AL: Attention-deficit/hyperactivity disorder and inflammation: What does current knowledge tell Us? A systematic review. Front Psychiatry 8: 228, 2017.

148. Darwish AH, Elgohary TM and Nosair NA: Serum interleukin-6 level in children with attention-deficit hyperactivity disorder (ADHD). J Child Neurol 34: 61-67, 2019.

149. Donfrancesco R, Nativio P, Borrelli E, Giua E, Andriola E, Villa MP and DI Trani M: Serum cytokines in paediatric neuropsychiatric syndromes: Focus on attention deficit hyperactivity disorder. Minerva Pediatr: 2016 (Epub ahead of print)

150. O'Shea TM, Joseph RM, Kuban KC, Allred EN, Ware J, Coster T, Fichorova RN, Dammann O and Leviton A; ELGAN Study Investigators: Elevated blood levels of inflammation-related proteins are associated with an attention problem at age $24 \mathrm{mo}$ in extremely preterm infants. Pediatr Res 75: 781-787, 2014.

151. Donfrancesco R, Nativio P, Di Benedetto A, Villa MP, Andriola E, Melegari MG, Cipriano E and Di Trani M: Anti-yo antibodies in children with ADHD: First results about serum cytokines. J Atten Disord 2016 (Epub ahead of print)
152. Oades RD, Dauvermann MR, Schimmelmann BG, Schwarz MJ and Myint AM: Attention-deficit hyperactivity disorder (ADHD) and glial integrity: S100B, cytokines and kynurenine metabolism-effects of medication. Behav Brain Funct 6: 29, 2010.

153. Rand KM, Austin NC, Inder TE, Bora S and Woodward LJ: Neonatal infection and later neurodevelopmental risk in the very preterm infant. J Pediatr 170: 97-104, 2016.

154. van Tilborg E, Heijnen CJ, Benders MJ, van Bel F, Fleiss B, Gressens P and Nijboer CH: Impaired oligodendrocyte maturation in preterm infants: Potential therapeutic targets. Prog Neurobiol 136: 28-49, 2016.

155. Vogel SWN, Bijlenga D, Verduijn J, Bron TI, Beekman ATF, Kooij JJS and Penninx BWJH: Attention-deficit/hyperactivity disorder symptoms and stress-related biomarkers. Psychoneuroendocrinology 79: 31-39, 2017.

156. Chudal R, Brown AS, Gyllenberg D, Hinkka-Yli-Salomaki S, Sucksdorff M, Surcel HM, Upadhyaya S and Sourander A: Maternal serum C-reactive protein (CRP) and offspring attention deficit hyperactivity disorder (ADHD). Eur Child Adolesc Psychiatry 29: 239-247, 2020.

157. Kozlowska A, Wojtacha P, Rowniak M, Kolenkiewicz M and Huang ACW: ADHD pathogenesis in the immune, endocrine and nervous systems of juvenile and maturating SHR and WKY rats. Psychopharmacology (Berl) 236: 2937-2958, 2019.

158. Saedisomeolia A, Samadi M, Gholami F, Seyedi M, Effatpanah M, Hashemi R, Abdolahi M and Honarvar NM: Vitamin d's molecular action mechanism in attention-deficit/ hyperactivity disorder: A review of evidence. CNS Neurol Disord Drug Targets 17: 280-290, 2018.

159. Verlaet AAJ, Maasakkers CM, Hermans N and Savelkoul HFJ: Rationale for dietary antioxidant treatment of ADHD. Nutrients 10: E405, 2018

160. Cortese S and Angriman M: Attention-deficit/hyperactivity disorder, iron deficiency, and obesity: Is there a link? Postgrad Med 126: 155-170, 2014

161. Kean JD, Camfield D, Sarris J, Kras M, Silberstein R, Scholey A and Stough C: A randomized controlled trial investigating the effects of PCSO-524, a patented oil extract of the New Zealand green lipped mussel (Perna canaliculus), on the behaviour, mood, cognition and neurophysiology of children and adolescents (aged 6-14 years) experiencing clinical and sub-clinical levels of hyperactivity and inattention: Study protocol ACTRN12610000978066. Nutr J 12: 100, 2013.

162. Ghunaim N, Gronlund H, Kronqvist M, Gronneberg R, Soderstrom L, Ahlstedt S and van Hage-Hamsten M: Antibody profiles and self-reported symptoms to pollen-related food allergens in grass pollen-allergic patients from northern Europe. Allergy 60: 185-191, 2005.

163. Zhou L, Chen L, Li X, Li T, Dong Z and Wang YT: Food allergy induces alteration in brain inflammatory status and cognitive impairments. Behav Brain Res 364: 374-382, 2019.

164. de Theije CG, Bavelaar BM, Lopes da Silva S, Korte SM, Olivier B, Garssen J and Kraneveld AD: Food allergy and food-based therapies in neurodevelopmental disorders. Pediatr Allergy Immunol 25: 218-226, 2014.

165. Sarlus H, Höglund CO, Karshikoff B, Wang X, Lekander M, Schultzberg M and Oprica M: Allergy influences the inflammatory status of the brain and enhances tau-phosphorylation. J Cell Mol Med 16: 2401-2412, 2012

166. Niggemann B, Reibel S, Roehr CC, Felger D, Ziegert M, Sommerfeld C and Wahn U: Predictors of positive food challenge outcome in non-IgE-mediated reactions to food in children with atopic dermatitis. J Allergy Clin Immunol 108: 1053-1058, 2001.

167. Milosz M, Demkow U and Wolanczyk T: Relation between attention-deficit hyperactivity disorder and IgE-dependent allergy in pediatric patients. Adv Exp Med Biol 1096: 105-109, 2018.

168. Jiang X, Shen C, Dai Y, Jiang F, Li S, Shen X, Hu Y and Li F: Early food allergy and respiratory allergy symptoms and attention-deficit/hyperactivity disorder in Chinese children: A cross-sectional study. Pediatr Allergy Immunol 29: 402-409, 2018.

169. Boris M and Mandel FS: Foods and additives are common causes of the attention deficit hyperactive disorder in children. Ann Allergy 72: 462-468, 1994.

170. Verlaet AA, Noriega DB, Hermans $N$ and Savelkoul HF: Nutrition, immunological mechanisms and dietary immunomodulation in ADHD. Eur Child Adolesc Psychiatry 23: $519-529,2014$ 
171. Ritz BW and Lord RS: Case study: The effectiveness of a dietary supplement regimen in reducing IgG-mediated food sensitivity in ADHD. Altern Ther Health Med 11: 72-75, 2005.

172. Miyazaki C, Koyama M, Ota E, Swa T, Mlunde LB, Amiya RM Tachibana Y, Yamamoto-Hanada K and Mori R: Allergic diseases in children with attention deficit hyperactivity disorder: A systematic review and meta-analysis. BMC Psychiatry 17: 120, 2017.

173. Johnston LK, Chien KB and Bryce PJ: The immunology of food allergy. J Immunol 192: 2529-2534, 2014.

174. Pelsser LM, Buitelaar JK and Savelkoul HF: ADHD as a (non) allergic hypersensitivity disorder: A hypothesis. Pediatr Allergy Immunol 20: 107-112, 2009.

175. Suwan P, Akaramethathip D and Noipayak P: Association between allergic sensitization and attention deficit hyperactivity disorder (ADHD). Asian Pac J Allergy Immunol 29: 57-65, 2011

176. Rijnierse A, Nijkamp FP and Kraneveld AD: Mast cells and nerves tickle in the tummy: Implications for inflammatory bowel disease and irritable bowel syndrome. Pharmacol Ther 116 : 207-235, 2007.

177. Gui XY: Mast cells: A possible link between psychological stress, enteric infection, food allergy and gut hypersensitivity in the irritable bowel syndrome. J Gastroenterol Hepatol 13: 980-989, 1998.

178. Hirano T, Taga T, Nakano N, Yasukawa K, Kashiwamura S, Shimizu K, Nakajima K, Pyun KH and Kishimoto T: Purification to homogeneity and characterization of human B-cell differentiation factor (BCDF or BSFp-2). Proc Natl Acad Sci USA 82: 5490-5494, 1985.

179. Li X, Chauhan A, Sheikh AM, Patil S, Chauhan V, Li XM, Ji L, Brown T and Malik M: Elevated immune response in the brain of autistic patients. J Neuroimmunol 207: 111-116, 2009.

180. Needham BD, Tang W and Wu WL: Searching for the gut microbial contributing factors to social behavior in rodent models of autism spectrum disorder. Dev Neurobiol 78: 474-499, 2018.

181. Meeking MM, MacFabe DF, Mepham JR, Foley KA, Tichenoff LJ, Boon FH, Kavaliers M and Ossenkopp KP. Propionic acid induced behavioural effects of relevance to autism spectrum disorder evaluated in the hole board test with rats. Prog Neuropsychopharmacol Biol Psychiatry 97: 109794, 2020.

182. Zass LJ, Hart SA, Seedat S, Hemmings SM and Malan-Muller S: Neuroinflammatory genes associated with post-traumatic stress disorder: Implications for comorbidity. Psychiatr Genet 27: 1-16, 2017.

183. Nakamura Y, Ishimaru K, Shibata S and Nakao A: Regulation of plasma histamine levels by the mast cell clock and its modulation by stress. Sci Rep 7: 39934, 2017.

184. Passos IC, Vasconcelos-Moreno MP, Costa LG, Kunz M, Brietzke E, Quevedo J, Salum G, Magalhaes PV, Kapczinski F and Kauer-Sant'Anna M: Inflammatory markers in post-traumatic stress disorder: A systematic review, meta-analysis, and meta-regression. Lancet Psychiatry 2: 1002-1012, 2015.

185. Geracioti TD Jr, Carpenter LL, Owens MJ, Baker DG, Ekhator NN, Horn PS, Strawn JR, Sanacora G, Kinkead B, Price LH and Nemeroff CB: Elevated cerebrospinal fluid substance $\mathrm{p}$ concentrations in posttraumatic stress disorder and major depression. Am J Psychiatry 163: 637-643, 2006.

186. O'Donovan A, Cohen BE, Seal KH, Bertenthal D, Margaretten M, Nishimi K and Neylan TC: Elevated risk for autoimmune disorders in Iraq and afghanistan veterans with posttraumatic stress disorder. Biol Psychiatry 77: 365-374, 2015.
187. Hendriksen E, van Bergeijk D, Oosting RS and Redegeld FA: Mast cells in neuroinflammation and brain disorders. Neurosc Biobehav Rev 79: 119-133, 2017.

188. Ahmed ME, Iyer S, Thangavel R, Kempuraj D, Selvakumar GP, Raikwar SP, Zaheer S and Zaheer A: Co-localization of glia maturation factor with NLRP3 inflammasome and autophagosome markers in human Alzheimer's disease brain. J Alzheimers Dis 60: 1143-1160, 2017.

189. Xiong Z, Thangavel R, Kempuraj D, Yang E, Zaheer S and Zaheer A: Alzheimer's disease: Evidence for the expression of interleukin-33 and its receptor ST2 in the brain. J Alzheimers Dis 40: 297-308, 2014.

190. Shaik-Dasthagirisaheb YB and Conti P: The role of mast cells in Alzheimer's disease. Adv Clin Exp Med 25: 781-787, 2016.

191. Tagen M, Elorza A, Kempuraj D, Boucher W, Kepley CL, Shirihai OS and Theoharides TC: Mitochondrial uncoupling protein 2 inhibits mast cell activation and reduces histamine content. J Immunol 183: 6313-6319, 2009.

192. Nelson RB, Siman R, Iqbal MA and Potter H: Identification of a chymotrypsin-like mast cell protease in rat brain capable of generating the N-terminus of the Alzheimer amyloid beta-protein. J Neurochem 61: 567-577, 1993.

193. Ibrahim MZ, Reder AT, Lawand R, Takash W and Sallouh-Khatib S: The mast cells of the multiple sclerosis brain. J Neuroimmunol 70: 131-138, 1996

194. Russi AE and Brown MA: The meninges: New therapeutic targets for multiple sclerosis. Transl Res 165: 255-269, 2015.

195. Theoharides TC, Asadi S, Panagiotidou S and Weng Z: The 'missing link' in autoimmunity and autism: Extracellular mitochondrial components secreted from activated live mast cells. Autoimmun Rev 12: 1136-1142, 2013.

196. Kawasaki H, Chang HW, Tseng HC, Hsu SC, Yang SJ, Hung CH, Zhou Y and Huang SK: A tryptophan metabolite, kynurenine, promotes mast cell activation through aryl hydrocarbon receptor. Allergy 69: 445-452, 2014.

197. Hermine O, Lortholary O, Leventhal PS, Catteau A, Soppelsa F, Baude C, Cohen-Akenine A, Palmerini F, Hanssens K, Yang Y, et al: Case-control cohort study of patients' perceptions of disability in mastocytosis. PLoS One 3: e2266, 2008 .

198. Georgin-Lavialle S, Moura DS, Salvador A, Chauvet-Gelinier JC, Launay JM, Damaj G, Cote F, Soucie E, Chandesris MO, Barete S, et al: Mast cells' involvement in inflammation pathways linked to depression: Evidence in mastocytosis. Mol Psychiatry 21: 1511-1516, 2016.

199. Couturier N, Zappulla JP, Lauwers-Cances V, Uro-Coste E, Delisle MB, Clanet M, Montagne L, Van der Valk P, Bö L and Liblau RS: Mast cell transcripts are increased within and outside multiple sclerosis lesions. J Neuroimmunol 195: 176-185, 2008.

This work is licensed under a Creative Commons Attribution-NonCommercial-NoDerivatives 4.0 International (CC BY-NC-ND 4.0) License. 